\title{
Personalities and health in older cat and dog owners: A HUNT-study
}

\author{
Ingela Enmarker ${ }^{1,2^{*}}$, Ove Hellzén ${ }^{2,3}$, Knut Ekker $^{4}$, Anne-Grethe T. Berg ${ }^{5}$ \\ ${ }^{1}$ Faculty of Health Sciences, Nord-Trøndelag University College, Namsos, Norway; \\ *Corresponding Author: ingela.enmarker@hint.no \\ ${ }^{2}$ Center for Care Research, Mid-Norway, Norway \\ ${ }^{3}$ Department of Health Sciences, Mid Sweden University, Sundsvall, Sweden \\ ${ }^{4}$ Faculty of Agriculture and Information Technology, Nord-Trøndelag University College, Steinkjer, Norway \\ ${ }^{5}$ Norwegian Food Safety Authority, Steinkjer, Norway
}

Received 18 June 2013; revised 18 July 2013; accepted 15 August 2013

Copyright (C) 2013 Ingela Enmarker et al. This is an open access article distributed under the Creative Commons Attribution License, which permits unrestricted use, distribution, and reproduction in any medium, provided the original work is properly cited.

\begin{abstract}
The aim of this population study was to identify personality traits among older (>65 years) male and female owners of cats and dogs and to compare their general health status in relation to their personality. Further, the aim was to examine whether current cat and dog ownership could be predicted by the owners' personality and health. Data were collected from the NorthTrøndelag Health Study (HUNT) in Norway. Included were a total of 1897 cat or dog owners between the ages of 65 years and 101 years. The results showed that there were a higher proportion of introverted male cat owners than extraverted ones. Moreover, a majority of women with cats reported that their health was not good. Furthermore, female cat owners who displayed higher scores on neurotic traits experienced significantly poorer health compared to those female cat owners that experienced good health. The same was true for female cat owners who considered themselves to be introverted. Neither personality nor health could predict pet-ownership, but it was more likely for older individuals (80 101 years) to own a cat than a dog. This study has shown that human personality is associated with cat and dog ownership, but there are other factors connected with pet ownership as well.
\end{abstract}

Keywords: Pet Ownership; Cats and Dogs; Health; Personality; Old Age; Population Study

\section{INTRODUCTION}

Diseases and dysfunctions increase with older age [1].
A number of studies have demonstrated that pets enhance older people's health [2-5]. Enmarker et al. [6] found that this was true for older owners of dogs but not for older owners of cats. However, differences in personality may affect self-perceptions of health [7]. For example, Weiss and Costa [8] showed that neuroticism may be a protective factor for physical illness. Conversely, studies found that neuroticism could predict poorer physical health and poorer subjective well-being [9-11]; yet other studies have not shown any relationship between the two at all [12]. Because of these conflicting results, Metha and Gosling [13] suggest that additional factors may explain the effect of neuroticism on health.

It is assumed that the preference for pets as either cats or dogs varies with the individual's personality [14]. In accordance, Gosling, Sandy and Potter [15] found that people who considered themselves to be "dog people" were more extroverted than "cat people", while the latter were more neurotic. When comparing pet and non-pet ownership, Parslow et al. [16] found that older men who own pets were more extroverted than those without animals. But the findings are not consistent. Johnson and Rule [17] did not find any differences between "dog people" and "cat people".

Studies of personality have been guided by different perspectives [18]. The major approach is the trait theory, which believes that personality consists of traits that make individuals behave and react in a certain way depending on a dominant characteristic trait. Human personalities can be divided into different dimensions such as extraversion (vs. introversion) and neuroticism (emotional stability vs. instability) $[19,20]$. Extraversion includes assertiveness, adventurousness, sociability, outgoingness, and positive emotions, while neuroticism consists of anxiety, irritability, moodiness, shyness, vulnerability, and depres- 
sion [21]. In a cross-cultural comparison of people aged 16 - 60 years in Norway and England, Eysenck and Tambs [22] found that both Norwegian men and women were less likely to be neurotic than those participants from England. Other studies have shown that women are more likely to be neurotic compared to men $[23,24]$. While research has shown differences in specific issues, it has not found any general gender differences in extroversion [25].

Srivastava et al. [26] found that, compared to younger people, older people are more emotionally stable with age, but also have a tendency toward greater introversion [27-29]. However, most longitudinal studies indicate that human personality characteristics are stable throughout adult life [30-32].

Since there is a lack of studies with large samples that examine the relationship between pets, older peoples' personalities and health, the aim of this population study was to identify personality traits among older ( $>65$ years) male and female owners of cats and dogs and to compare their general health status in relation to their personality. Further, the aim was to examine if current cat and dog ownership could be predicted by personality and/or health.

\section{METHOD}

\subsection{Sample Population}

The present cross-sectional population study from the North-Trøndelag Health Study (HUNT) in Norway included a total of 1897 cat or dog owners between 65 years and 101 years of age $(\mathrm{M}=74.8, \mathrm{SD}=6.45)$. In Table 1 the distribution of pet ownership between cats and dogs can be seen. This HUNT study was carried out between 2006 and 2008 in Nord-Trøndelag County. It is one of 19 counties in Norway and contains $3 \%$ of the national population. The county is fairly representative of Norway as a whole when demographic and geographical factors are considered but it contains no big cities.

From the descriptions of the pet owners, it can be seen that the proportion of cat owners is highest among the oldest segment ( 80 years - 101 years). Otherwise, there were no significant differences in the demographics of dog owners and cat owners.

\subsection{Measures}

Besides age, gender and marital status, there were questions about pets, personality and general selfrated health status.

\subsubsection{Questions about Animals/Pets}

There was one question about pets/animals: Are there any pets in your home? (cat, dog, other fur-bearing animal/bird).
Table 1. Demographics of cat and dog ownership in numbers and percentage.

\begin{tabular}{|c|c|c|c|}
\hline \multicolumn{4}{|c|}{ Pet ownership ( $\mathrm{N}=1897)$} \\
\hline & Cats & Dogs & $\mathrm{Chi}^{2}$ \\
\hline \multicolumn{4}{|l|}{ Gender } \\
\hline Women & $547(59.3)$ & $375(40.7)$ & \\
\hline Men & $536(55.0)$ & $439(45.0)$ & 3.67 \\
\hline \multicolumn{4}{|l|}{ Age groups } \\
\hline $65-79$ & $870(54.6)$ & $722(45.4)$ & \\
\hline $80-101$ & $213(69.8)$ & $92(30.2)$ & $24.10^{* * *}$ \\
\hline \multicolumn{4}{|l|}{ Marital status } \\
\hline $\begin{array}{l}\text { Married/ } \\
\text { cohabitant }\end{array}$ & $788(55.8)$ & $624(44.2)$ & \\
\hline Living alone & $238(60.1)$ & $158(39.9)$ & 2.32 \\
\hline $\begin{array}{c}\text { Married/ } \\
\text { cohabitant } \\
\text { Women }\end{array}$ & $333(56.5)$ & $256(43.5)$ & \\
\hline Men & $455(55.3)$ & $368(44.7)$ & 0.22 \\
\hline \multicolumn{4}{|l|}{ Living alone } \\
\hline Women & $169(63.3)$ & $98(36.7)$ & \\
\hline Men & $69(53.5)$ & $60(46.5)$ & 3.49 \\
\hline
\end{tabular}

Note. Marital status will not be used in further analysis; ${ }^{* * *} p<0.001$.

Since the aim was to compare cat and dog ownership, owners of other fur-bearing animals and bird owners were excluded.

\subsubsection{Personality}

To measure extraversion (versus introversion) and neuroticism (emotional stability versus emotional instability), an abbreviated form of the Eysenck Personality Questionnaire (EPQ) was used. Extroversion (E) was measured by six questions about how social the person claims to be $(\alpha=0.70)$. Neuroticism (N) was measured by six questions on emotional stability $(\alpha=0.71)$. Only those people who had answered all six questions were included in the analyses. From previous HUNT 3 studies [33], E was classified as low, introversion $(0-3)$ and high, extraversion (4 - 6); and $\mathrm{N}$ was classified as low, emotional stability $(0-2)$ and high, emotional instability $(3-6)$ in the analyses. The mean for people aged 65 years and above included in the present HUNT 3 study was for Extraversion 3.08, and for Neuroticism 1.61.

\subsubsection{Self-Rated General Health Status}

The participants' self-rated general health status was graded into one of four response alternatives (very good, good, poor, and very poor). For the analyses, the alternatives were pooled into good (very good and good) and poor (poor and very poor) health.

\subsection{Data Analysis}

For the two first aims, Pearson chi-squared statistic analyses were performed. In the analyses of health, age was controlled for. For the final aim, a logistic regression 
model was carried out. The computer program SPSS for Windows (version 19.0) was used and the $p$-value 0.05 was used as the level of significance for all analyses.

\subsection{Ethical Considerations}

HUNT-3 was permitted by the Norwegian Data Inspectorate and by the Regional Committee for Medical Research. All participants in HUNT-3 gave written informed consent. Moreover, the present study was approved by the Board of Research Ethics in Health Region IV of Norway, reference number 2009/813-2.

\section{RESULT}

\subsection{Personality in Cat and Dog Owners}

The first aim was to compare older male and female cat and dog owners on measures of extraversion and neuroticism. Independent of pet ownership, the share of selfrated extraverted persons in our sample was $50.7 \%$. The corresponding figure for neuroticism was $13.7 \%$. There were more women $(\mathrm{n}=163)$ who displayed high neurotic traits than men $(\mathrm{n}=84), p<0.001$. For extroversion, however, there were no gender differences $(p>0.05)$. Women $(n=467)$ and men $(n=448)$.

In Table 2 we see that among cat owners, there was a higher proportion of men who rated themselves as introverted rather than as extroverted. For neuroticism there were no significant gender differences. However, when comparing men and women with a high degree of selfestimated neurotic traits, there was a strong tendency of association: $61 \%$ of women were cat owners compared to $51.7 \%$ of the men $(p=0.051)$.

Table 2. The proportion of Cat and Dog owners in association to Personality and Gender presented in number and percentage, with Chi-2 statistics.

\begin{tabular}{ccccc}
\hline Gender & Personality & $\begin{array}{c}\text { Cat owner } \\
\text { N (percent) }\end{array}$ & $\begin{array}{c}\text { Dog owner } \\
\text { N (percent) }\end{array}$ & Chi $^{2}$ \\
\hline \multirow{2}{*}{ Women } & Extraversion & & & \\
& Low & $310(60.7)$ & $201(39.3)$ & \\
Men & High & $212(57.1)$ & $159(42.9)$ & 1.104 \\
& Low & $319(57.6)$ & $235(42.4)$ & \\
\multirow{6}{*}{ Women } & High & $195(51.0)$ & $87(49.0)$ & $3.899^{*}$ \\
& Total & $1036(57.0)$ & $782(43.0)$ & \\
& Leuroticism & & & \\
\multirow{6}{*}{ Men } & High & $177(61.0)$ & $113(39.9)$ & 0.507 \\
& Low & $416(55.2)$ & $337(44.8)$ & \\
& High & $69(51.7)$ & $83(48.3)$ & 0.693 \\
& Total & $1022(56.9)$ & $774(43.1)$ & \\
\hline
\end{tabular}

Note. Internal dropouts Extraversion $=79$ and Neuroticism $=101 ;{ }^{*} p \leq 0.05$.

\subsection{The Association between Personality and General Health Status in Cat and Dog Owners}

The next step was to compare female and male owners of cats and dogs for self-reported general health status (not good/good) in relation to their personality. In Tables $\mathbf{3}$ and $\mathbf{4}$ women and men are separated.

Table 3. Cat and dog owners' self reported General Health Status in relation to Extraversion and Gender.

\begin{tabular}{ccccc}
\hline \multirow{2}{*}{$\begin{array}{c}\text { Health } \\
\text { Women }\end{array}$} & $\begin{array}{c}\text { Cat owner } \\
\text { N (percent) }\end{array}$ & $\begin{array}{c}\text { Dog owner } \\
\text { N(percent) }\end{array}$ & Chi $^{2}$ \\
\hline \multirow{2}{*}{ Low } & Not good & $151(65.1)$ & $81(34.9)$ & \\
& Good & $135(54.0)$ & $115(46.0)$ & $6.129^{*}$ \\
& Total & $286(59.3)$ & $196(40.7)$ & \\
High & Not good & $82(59.0)$ & $57(41.0)$ & \\
& Good & $116(56.0)$ & $91(44.0)$ & 0.296 \\
& Total & $198(57.2)$ & $148(42.8)$ & \\
Men & & & & \\
& Not good & $114(55.1)$ & $93(44.9)$ & \\
& Good & $188(60.1)$ & $125(39.9)$ & 3.696 \\
& Total & $302(58.1)$ & $218(41.9)$ & \\
High & Not good & $66(58.9)$ & $46(41.1)$ & \\
& Good & $121(48.0)$ & $131(52.0)$ & 1.275 \\
& Total & $187(51.4)$ & $177(48.6)$ &
\end{tabular}

Note. Internal dropouts $=185 ;{ }^{*} p \leq 0.05$.

Table 4. Cat and dog owners' self reported general health in relation to Neuroticism and Gender.

\begin{tabular}{|c|c|c|c|c|}
\hline & Health & $\begin{array}{c}\text { Cat owner } \\
\text { N (percent) }\end{array}$ & $\begin{array}{l}\text { Dog owner } \\
\text { N (percent) }\end{array}$ & $\mathrm{Chi}^{2}$ \\
\hline \multicolumn{5}{|c|}{ Neuroticism } \\
\hline \multicolumn{5}{|c|}{ Women } \\
\hline \multirow{2}{*}{ Low } & Not good & 125 (61.3) & 79 (38.7) & \\
\hline & Good & $192(56.0)$ & $151(44.0)$ & 1.473 \\
\hline \multirow{4}{*}{ High } & Total & $317(58.0$ & $230(42.0)$ & \\
\hline & Not good & $105(64.8)$ & $57(35.2)$ & \\
\hline & Good & $57(52.8)$ & $51(47.2)$ & $3.912^{*}$ \\
\hline & Total & $162(60.0)$ & $108(40.0)$ & \\
\hline \multicolumn{5}{|l|}{ Men } \\
\hline \multirow{2}{*}{ Low } & Not good & $126(57.3)$ & $94(42.7)$ & \\
\hline & Good & $270(54.8)$ & $223(45.2)$ & 0.387 \\
\hline \multirow{4}{*}{ High } & Total & $396(55.5)$ & $317(44.5)$ & \\
\hline & Not good & $49(52.7)$ & $44(47.3)$ & 0.002 \\
\hline & Good & $35(53.0)$ & $31(47.0)$ & \\
\hline & Total & $84(52.8)$ & $75(47.2$ & \\
\hline
\end{tabular}

Note. Internal dropouts $=208 ;{ }^{*} p \leq 0.05$. 
When distributed by general health status and extraversion, it was shown that significantly more female cat owners were introverted; these women also reported poor health $(65.1 \%$ of introverted women who were in poor health were cat owners compared with $54.0 \%$ of introverted women with good health). For men there were no such differences for introverts and extroverts, but when comparing not good/good health ratings there was a tendency $(p=0.055)$ for men who rated their health as not good to also be cat owners.

For women, the pattern of neuroticism was almost the same as for extraversion, namely less emotionally stable women (exhibiting high neuroticism) that rated their health as not good also reported a significantly higher percentage of cat ownership (64.8\%) compared to the less emotionally stable female cat owners with good health $(52.8 \%)$. There were no significant differences among neurotic men.

The shares of cat ownership among emotionally unstable women and men who reported a "not good" health status were, respectively, $64.8 \%$ versus $52.7 \%(p=0.057)$. In all analyses, age was controlled for, but did not alter the results.

\subsection{Predictions of Personality and Health on Pet Ownership}

The final step was to examine whether current dog and cat ownership among older women and men could be predicted by personality and health. From the previous chi-squared statistic analyses interactions were constructed in the model. Since health could decrease with older age the interaction health and age was also added. Otherwise, age and gender were controlled for as separate variables.

Table 5 illustrates the result in the logistic regression model. Neither personality nor health could predict petownership. However, it was more likely for older individuals (80 - 101 years) to own a cat than a dog. This result did not change when the interactions were added. None of the included interactions were significant.

\section{DISCUSSION}

According to Kidd and Kidd [14], preferences for pets might be explained by human personality. Our results demonstrate that cat ownership is more associated than dog ownership with introversion and self-rated neurotic traits among older persons. Dog ownership has a stronger association with extraversion. To be more precise, there were a higher proportion of introverted male cat owners than extraverted ones. When we compared high scores for neuroticism, pet ownership and gender, there was a strong tendency of significant association $(p=0.051)$ : in short, the proportion of neurotic women who owned a cat was larger than comparable male cat owners. Research has not shown any general gender differences in extraversion [25], nor did our study find any. However, there

Table 5. Result from logistic regression with cat (0) and dog ownership (1) as dependent variable.

\begin{tabular}{|c|c|c|c|c|c|c|c|c|c|}
\hline \multirow[t]{2}{*}{ Included } & \multicolumn{3}{|l|}{ Model 1} & \multicolumn{3}{|l|}{ Model 2} & \multicolumn{3}{|l|}{ Model 3} \\
\hline & OR & Wald & $95 \%$ CI & OR & Wald & $95 \% \mathrm{CI}$ & OR & Wald & $95 \%$ CI \\
\hline $\begin{array}{c}\text { Extraversion } \\
(\text { low }=0, \text { High }=1)\end{array}$ & 1.163 & 2.254 & $0.955-1.417$ & 1.163 & 2.250 & $0.955-1.417$ & 1.130 & 1.047 & $0.894-1.427$ \\
\hline $\begin{array}{c}\text { Neuroticism } \\
(\text { low }=0, \text { High }=1)\end{array}$ & 1.117 & 0.541 & $0.832-1.499$ & 1.117 & 0.540 & $0.832-1.499$ & 1.050 & 0.086 & $0.757-1.456$ \\
\hline $\begin{array}{c}\text { Health } \\
(\text { poor }=0, \text { Good }=1)\end{array}$ & 1.167 & 2.218 & $0.952-1.430$ & 1.172 & 2.024 & $0.942-1.458$ & 1.130 & 1.004 & $0.890-1.436$ \\
\hline $\begin{array}{c}\text { Gender } \\
(\text { female }=0, \text { Male }=1)\end{array}$ & 1.128 & 1.436 & $0.926-1.375$ & 1.128 & 1.435 & $0.926-1.375$ & 1.079 & 0.391 & $0.851-1.368$ \\
\hline Constant & & & & & & & & & \\
\hline $\begin{array}{c}\text { Health x Age-groups } \\
\text { Constant }\end{array}$ & $0.658^{* * *}$ & 13.102 & & $\begin{array}{c}0.971 \\
0.656^{* * *}\end{array}$ & $\begin{array}{c}0.010 \\
12.692\end{array}$ & $0.544-1.731$ & 0.975 & 0.007 & $0.547-1.739$ \\
\hline $\begin{array}{c}\text { Extroversion x Health x Gender } \\
\text { Neuroticism x Health } x \text { Gender } \\
\text { Constant }\end{array}$ & & & & & & & $\begin{array}{c}1.088 \\
1.365 \\
0.688^{* *}\end{array}$ & $\begin{array}{l}0.205 \\
0.642 \\
7.605\end{array}$ & $\begin{array}{l}0.756-1.565 \\
0.637-2.924\end{array}$ \\
\hline
\end{tabular}

Note: Model 3: $\mathrm{R}^{2}$ (Nagelkerke) $=0.027$; Hosmer \& Lemeshow $=0.38$. Model $\chi^{2}=34.339 ;{ }^{* * *} p \leq 0.001,{ }^{* *} p \leq 0.01$. 
were a significantly higher proportion of introverted male cat owners than extraverted ones. Conversely, there were a larger proportion of extraverted male dog owners. A similar pattern was found among women, yet without any significant differences.

It might be assumed that cat owners would be more independent than dog owners, since cats are more selfregulating pets compared to dogs [34]. However, there are other perspectives as well. On the one hand, dogs require training, and dog walking is often linked to contact with other people [4]. Dog ownership therefore might require sociability in the owner's personality. Introverted individuals may be more reluctant to own a dog. They might find that a cat is a better alternative if they want to avoid daily contacts with others. On the other hand, a dog may help the person to be more outgoing and less isolated [4], thereby resulting in better health [6].

Moreover, in our study, a majority of the emotional unstable and introvert women with cats reported their health as not good. Other studies have found that neuroticism is related to poor physical health and subjective well-being [9-11]. The World Health Organization (WHO) [35] has defined health as "a state of complete physical, mental, and social well-being". That is, health has a broader meaning than just an absence of disease or infirmity. In this HUNT study, we do not know the participants' own interpretation of "health". Our study only shows correlations; there could be other confounding factors as well.

Metha and Gosling [13] suggested that an additional factor could explain the effect of neuroticism on health. Since a cat does not demand any particular physical activity of its owner, the cat owner may not be forced to get outdoors daily and for that reason does not feel quite healthy. Conversely, it could be that a cat is a suitable pet for people that are not healthy. However, poor or good health did not predict pet-ownership in the present study, but older elderly individuals ( 80 year - 101 years) were more likely to own a cat than a dog. In general, health decreases with older age [1]. This suggests that a cat is better suited to older elderly people than to younger elderly persons who generally are more physically active. Nevertheless, the interaction health and age did not predict any cat or dog ownership.

\section{CONCLUSION}

This study has shown that human personality and ownership of cats and dogs are associated, but that the personality is not the only factor connected with pet ownership. Our results only demonstrate correlations and are limited by the lack of surveying participants in big cities. The participation of urban dwellers would provide a more nuanced picture of older pet owners in Norway. However, in further HUNT studies, we will continue to expand our knowledge on older male and female owners of cats and dogs in this rural area by examining different aspects of their physical and mental health.

\section{ACKNOWLEDGEMENTS}

Data were provided by the Nord-Trøndelag Health Study (The HUNT Study), which is a collaboration between HUNT Research Centre (Faculty of Medicine, Norwegian University of Science and Technology NTNU), Nord-Trøndelag County Council, Central Norway Health Authority, and the Norwegian Institute of Public Health.

\section{REFERENCES}

[1] World Health Organization (2012) Ageing and life course. www.who.int/ageing/index.html

[2] Sable, P. (1995) Pets, attachment, and well-being across the life cycle. Social Work, 40, 334-341.

[3] Friedmann, E. and Thomas, S.A. (1995) Pet ownership, social support, and one year survival after acute myocardial infarction in the Cardiac Arrhythmia Suppression Trial (CAST). The American Journal of Cardiology, 76, 1213-1217. doi:10.1016/S0002-9149(99)80343-9

[4] McNicholas, J. and Collis, G.M. (2000) Dogs as catalysts for social interaction: Robustness of the effect. British Journal of Psychology, 91, 61-70. doi: $10.1348 / 000712600161673$

[5] Nimer, J. and Lundahl, B. (2007) Animal-assisted therapy: A meta-analysis. Anthrozoös, 20, 225-238. doi:10.2752/089279307X224773

[6] Enmarker, I., Hellzen, O., Ekker, K. and Berg-Trønsdal, A.G. (2012) Health in older cat and dog owners: The HUNT-study. Scandinavian Journal of Public Health, 40, 718-724. doi:10.1177/1403494812465031

[7] Goodwin, R. and Engstrom, G. (2002) Personality and the perception of health in the general population. Psychological Medicine, 32, 325-332. doi:10.1017/S0033291701005104

[8] Weiss, A. and Costa, P. (2005) Domain and facet personality predictors of all-cause mortality among medicare patients aged 65 to 100. Psychosomatic Medicine, 67, 715-723. doi:10.1097/01.psy.0000181272.58103.18

[9] Gardner, J. and Oswald, A. (2004) How is mortality affected by money, marriage and stress? Journal of Health Economics, 23, 1181-1207. doi:10.1016/j.jhealeco.2004.03.002

[10] Held, B.S. (2004) The negative side of positive psychology. Journal of Humanistic Psychology, 44, 9-46. doi: $10.1177 / 0022167803259645$

[11] Friedman, H.S., Kern, M.L. and Reynolds, C.A. (2010) Personality and health, subjective well-being, and longevity. Journal of Personality, 78, 179-215. doi:10.1111/j.1467-6494.2009.00613.x

[12] Martin, L., Friedman, H. and Schwartz, J. (2007) Personality and mortality risk across the life span: The importance of conscientiousness as a biopsychosocial attribute. Health Psychology, 26, 428-436. doi:10.1037/0278-6133.26.4.428 
[13] Metha, P.H. and Gosling, S.D. (2008) Bridging human and animal research: A comparative approach to studies of personality and health. Brain, Behavior, and Immunity, 22, 651-661. doi:10.1016/j.bbi.2008.01.008

[14] Kidd, A.H. and Kidd, R.M. (1980) Personality characteristics and preferences in pet ownership. Psychological Reports, 46, 939-949. doi:10.2466/pr0.1980.46.3.939

[15] Gosling, S.D., Sandy, C.J. and Potter, J. (2010) Personality of Self-Identified "Dog People" and "Cat People". Anthrozoös, 23, 213-222. doi:10.2752/175303710X12750451258850

[16] Parslow, R.A., Jorm, A.F., Christensen, H., Rodgers, B. and Jacomb, P. (2005) Pet ownership and health in older adults: Findings from a survey of 2.551 community-based Australians aged 60 - 64. Gerontology, 51, 40-47. doi: $10.1159 / 000081433$

[17] Johnson, S.B. and Rule, W.R. (1991) Personality characteristics and self-esteem in pet owners and non-owners. International Journal of Psychology, 26, 241-252.

[18] Passer, W.M and Smith, R.E. (2004) Psychology: The science of mind and behavior. The Mcgraw Hill Companies Inc.

[19] Eysenck, H. and Eysenck, S. (1975) Manual of Eysenck Personality Questionnaire. Hodder and Stoughton, London.

[20] Costa Jr., P.T. and McCrae, R.R. (1982) An approach to the attribution of age, period, and cohort effects. Psychological Bulletin, 92, 238-250. doi:10.1037/0033-2909.92.1.238

[21] John, O.P. and Srivastava, S. (1999) The Big Five trait taxonomy: History, measurement, and theoretical perspectives. In Pervin, L.A. and John, O.P., Eds., Handbook of Personality: Theory and Research, Guilford Press, New York, 102-138.

[22] Eysenck, B.G. and Tambs, K. (1990) Cross-cultural comparison of personality: Norway and England. Scandinavian Journal of Psychology, 31, 191-197. doi:10.1111/j.1467-9450.1990.tb00830.x

[23] Costa Jr., P.T., Terraccino, A. and McCrae, R.R. (2001) Gender differences in personality traits across cultures: Robust and surprising findings. Journal of Personality and Social Psychology, 81, 322-331. doi:10.1037/0022-3514.81.2.322

[24] McCrae, R.R., Terracino, A. and 78 Members of the Personality Profiles of Cultures Project (2005) Universal features of personality traits from the observer's perspective. Data from 50 cultures. Journal of Personality and Social Psychology, 88, 547-561. doi:10.1037/0022-3514.88.3.547

[25] Chapman, B.P., Duberstein, P.R., Sörensen, S. and Lyness,
J.M. (2007) Gender differences in five factor model personality traits in an elderly cohort. Personality and Individual Differences, 43, 594-603. doi:10.1016/j.paid.2007.04.028

[26] Srivastava, S., John, O.P., Gosling, S.D. and Potter, J. (2003) Development of personality in early and middle adulthood: Set like plaster or persistent change? Journal of Personality and Social Psychology, 84, 1041-1053. doi:10.1037/0022-3514.84.5.1041

[27] Costa Jr., P.T. and McCrae, R.R. (1997) Longitudinal stability of adult personality. In Hogan R., Johnson, J. and Briggs, S., Eds., Handbook of Personality Psychology, Academic Press, San Diego, 269-290. doi:10.1016/B978-012134645-4/50012-3

[28] Helson, R., Jones, C. and Kwan, V.S.Y. (2002) Personality change over 40 years of adulthood: Hierarchical linear modeling analyses of two longitudinal samples. Journal of Personality and Social Psychology, 83, 752-766. doi:10.1037/0022-3514.83.3.752

[29] Roberts, B.W. and Mroczek. D. (2008) Personality trait change in adulthood. Current Directions in Psychological Science, 17, 31-35. doi:10.1111/j.1467-8721.2008.00543.x

[30] Fraley, R.C. and Roberts, B.W. (2005) Patterns of continuity: A dynamic model for conceptualizing the stability of individual differences in psychological constructs across the life course. Psychological Review, 112, 60-74. doi:10.1037/0033-295X.112.1.60

[31] Allemand, M., Zimprich, D. and Martin, M. (2008) Longterm correlated change in personality traits in old-age. Personality and Aging, 23, 545-557.

[32] Terracino, A., McCrea, R.R. and Costa Jr., P.T. (2010) Intra-individual change in personality stability and age. Journal of Research in Personality, 44, 31-37. doi:10.1016/j.jrp.2009.09.006

[33] Grav, S. Stordal, E., Romild, U. and Hellzèn, O. (2012) The relationship among neuroticism, extraversion, and depression in the HUNT study: In relation to age and gender. Issues in Mental Health Nursing, 33, 777-785. doi:10.3109/01612840.2012.713082

[34] Cavanaugh, L.A., Leonard, H.A. and Scammon, D.L. (2008) A tail of two personalities: How canine companions shape relationships and well-being. Journal of Business Research, 61, 469-479. doi:10.1016/j.jbusres.2007.07.024

[35] World Health Organization (1946) Preamble to the constitution of the World Health Organization as adopted by the International Health Conference, New York, 19-22 June, 1946. Official Records of the World Health Organization, 2, 100 . 